\title{
Pretreatment systemic inflammation response index is predictive of pathological complete response in patients with breast cancer receiving neoadjuvant chemotherapy
}

\author{
Jie Dong ${ }^{1}$, Qingqing Sun', Yueyin Pan², Nannan Lu², Xinghua Han ${ }^{1 *}$ and Qiong Zhou ${ }^{1 *}$
}

\begin{abstract}
Background: Inflammation plays an important role in tumor proliferation, metastasis, and resistance to chemotherapy. The systemic inflammation response index (SIRI), has been reported to be closely related to prognosis in many tumors, such as breast and gastric cancers. However, the predictive value of pretreatment SIRI on pathological complete response $(\mathrm{pCR})$ rates in patients with breast cancer treated with neoadjuvant chemotherapy (NAC) is unknown. This study examined the correlation between SIRI and pCR in patients with breast cancer receiving NAC and identified convenient and accurate predictive indicators for $\mathrm{pCR}$.

Methods: We retrospectively analyzed the clinicopathological parameters and pretreatment peripheral blood characteristics of the 241 patients with breast cancer who received NAC between June 2015 and June 2020. Receiver operating characteristic (ROC) curves were used to determine the optimal cutoff of SIRI. ROC curves were also plotted to verify the accuracy of inflammatory markers for $\mathrm{PCR}$ prediction. The chi-squared test was used to explore the relationships of SIRI with pCR and other clinicopathological parameters. Multivariate analyses were performed using a logistic regression model.

Results: Among the 241 patients, 48 (19.92\%) achieved pCR. pCR was significantly related to SIRI, the neutrophillymphocyte ratio (NLR), the lymphocyte-monocyte ratio (LMR), molecular subtypes and other clinicopathological parameters, such as BMI, clinical T and N staging, and histological grade. Multivariate analyses indicated that the clinical T and N staging, SIRI, and NLR were independent prognostic factors for pCR in patients with breast cancer. The area under the ROC curve for SIRI was larger than that for NLR. Compared to patients with SIRI $\geq 0.72$, patients with $\mathrm{SIRI}<0.72$ had a nearly 5 -fold higher chance of obtaining $\mathrm{PCR}$ (odds ratio $=4.999$, 95\% confidence interval $=$ $1.510-16.551, p=0.000)$.
\end{abstract}

Conclusions: Pretreatment SIRI is predictive of $\mathrm{PCR}$ in patients with breast cancer receiving NAC, and the index can assist physicians in formulating personalized treatment strategies.

\footnotetext{
* Correspondence: hxhmail@ustc.edu.cn; zq1845011172@163.com

'Department of Medical Oncology, Anhui Provincial Hospital affiliated to Anhui Medical University, Hefei 2300001, Anhui Province, China

Full list of author information is available at the end of the article
}

(c) The Author(s). 2021 Open Access This article is licensed under a Creative Commons Attribution 4.0 International License, which permits use, sharing, adaptation, distribution and reproduction in any medium or format, as long as you give appropriate credit to the original author(s) and the source, provide a link to the Creative Commons licence, and indicate if changes were made. The images or other third party material in this article are included in the article's Creative Commons licence, unless indicated otherwise in a credit line to the material. If material is not included in the article's Creative Commons licence and your intended use is not permitted by statutory regulation or exceeds the permitted use, you will need to obtain permission directly from the copyright holder. To view a copy of this licence, visit http://creativecommons.org/licenses/by/4.0/ The Creative Commons Public Domain Dedication waiver (http://creativecommons.org/publicdomain/zero/1.0/) applies to the data made available in this article, unless otherwise stated in a credit line to the data. 
Keywords: Breast cancer, Neoadjuvant chemotherapy, Systemic inflammation response index, SIRI, Pathological complete response

\section{Background}

Breast cancer is the most commonly diagnosed malignant tumor and leading major cause of cancer-related death in women [1]. Neoadjuvant chemotherapy (NAC), which was introduced toward the end of the twentieth century [2], aims to downstage locally advanced disease and make it operable, and it was subsequently extended to early breast cancer, in which it significantly improves the breast-conserving surgery rate $[3,4]$.

Pathological complete response (pCR) is widely used as a surrogate endpoint in patients with breast cancer who received NAC with the aim of accelerating the evaluation of new treatment strategies, which is closely related to disease-free survival (DFS) and overall survival (OS) $[5,6]$. A pooled analysis of the collaborative neoadjuvant breast cancer trial $(\mathrm{CTNeoBC})$ illustrated that patients with $\mathrm{pCR}$ had a significantly longer survival time than those with residual tumors [7]. The response to NAC is critical for predicting prognosis and choosing the optimal chemotherapies to avoid excessive therapy. Hence, it is of great importance to predict pCR in patients with breast cancer receiving NAC.

Inflammation, recognized as one of the 10 hallmarks of cancer, contributes to tumor proliferation, angiogenesis, metastasis, and resistance to chemotherapy. Several studies revealed that systemic inflammation markers, such as the neutrophil-lymphocyte ratio (NLR) and lymphocyte-monocyte ratio (LMR), are associated with pCR in breast cancer $[8,9]$. The systemic inflammation response index (SIRI) is an integrated indicator based on the counts of peripheral venous blood neutrophils, monocytes and lymphocytes that might reflect the status of the local immune response and systemic inflammation [10]. To date, the relationship between SIRI and pCR has rarely been reported [11]. SIRI was first reported by Qi et al. for its ability to predict the survival of patients with pancreatic cancer [10]. Later, SIRI was confirmed to be related to prognosis in many tumors such as gastric and breast cancer [12, 13]. However, the predictive value of SIRI for $\mathrm{pCR}$ remains unclear in breast cancer.

In view of these findings, this study is examined whether SIRI is a predictive factor for $\mathrm{pCR}$ in patients with breast cancer.

\section{Methods}

\section{Patients}

We retrospectively enrolled 241 patients with primary breast cancer who received NAC at the First Affiliated
Hospital of USTC between June 2015 and June 2020. We extracted detailed treatment information and clinical data for all patients from their medical records. The project was approved by the ethics committee of The First Affiliated Hospital of USTC. The requirement for informed consent was waived because of the retrospective nature of the study.

The inclusion criteria were as follows: (1) the availability of complete blood test results and pathological information; (2) receipt of NAC after diagnosis and surgical treatment, such as breast-conserving surgery or modified radical mastectomy; and (3) diagnosis via needle core biopsy before NAC.

The exclusion criteria were as follows: (1) ductal carcinoma in situ irrespective of the presence of microinvasion; (2) incomplete pathological or laboratory examination results; (3) distant metastases; (4) bilateral breast cancer or inflammatory breast cancer; (5) severe inflammatory diseases or complications. This study included patients receiving neoadjuvant therapy with sequential regimens featuring anthracyclines and/or taxanes. Patients with human epidermal growth factor receptor 2 (HER-2) overexpression received anti-HER-2 targeted neoadjuvant therapy (Fig. 1).

\section{Blood samples}

In all patients, peripheral venous blood samples were collected on an empty stomach within 1 week before NAC. SIRI is calculated using the counts of peripheral venous blood neutrophils $(\mathrm{N})$, monocytes $(\mathrm{M})$, and lymphocytes (L) as follows: SIRI $=\mathrm{N} \times \mathrm{M} / \mathrm{L}$. NLR, LMR and the absolute lymphocyte count (ALC) were determined. We performed all peripheral venous blood cells evaluations in our local institutional laboratory.

\section{Pathology}

We used the 8th edition of the American Joint Committee on Cancer staging manual to determine the clinical staging of all patients in this study. The estrogen receptor (ER) and progesterone receptor (PR) status were assessed via immunohistochemistry, and positivity was indicated by the staining of at least $1 \%$ of tumor cell nuclei in the sample. The HER-2 status was assessed via immunohistochemistry and/or fluorescence in situ hybridization. This study describes the criteria for the definition of HER-2 positivity [14]. According to the results of ER, PR, and HER-2 immunohistochemical staining, the molecular subtypes were divided into three groups: triple-negative (hormone receptor [HR]-/HER-2 


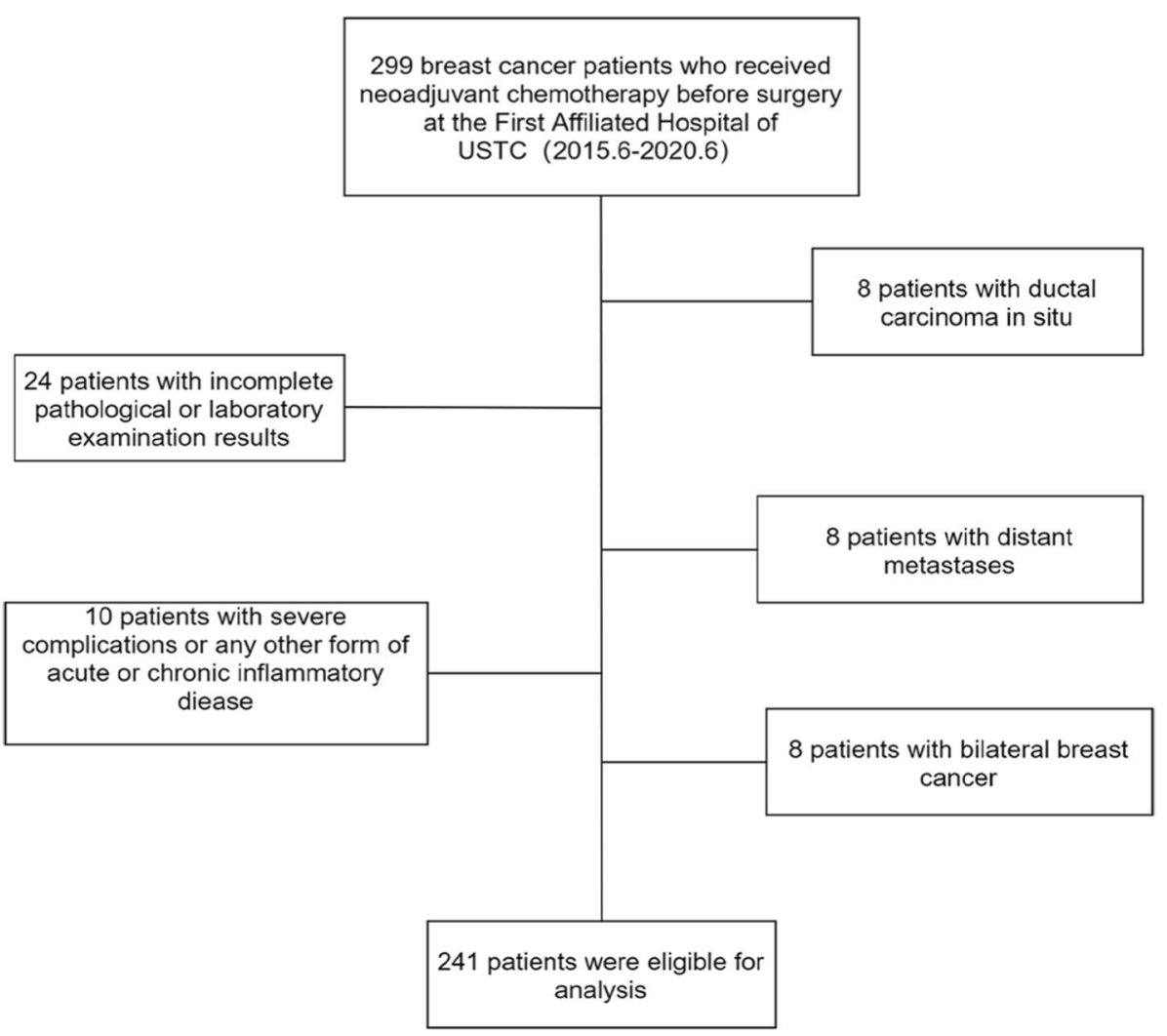

Fig. 1241 breast cancer patients were collected and the exclusion criteria

-), HER-2-positive (HR $\pm / \mathrm{Her}-2+)$ and HR-positive (HR+/HER-2-). We defined pCR as the absence of residual invasive cancer in surgical pathologic specimens (ypT0/ypTis and ypN0) [15].

\section{Statistical analysis}

Receiver operating characteristic (ROC) curve analysis was used to determine the optimal cutoffs for inflammatory markers (SIRI, NLR, LMR, ALC), and the ratio of the point with the highest Youden's index was defined as the best cutoff. ROC curves were also plotted to verify the accuracy of inflammatory markers for $\mathrm{pCR}$ prediction. The chi-squared test was used to assess the relationship between clinicopathological parameters and pCR. Logistic regression analysis was performed for multivariate analysis using an enter method. Statistical analysis was performed using SPSS version 22.0 software (IBM Corporation, Armonk, NY, USA) and GraphPad Prism version 7.0 software (GraphPad Software Inc., San Diego, CA, USA). $P<$ 0.05 was considered statistically significant.

\section{Results}

Clinicopathological parameters of all patients

We identified 299 patients with breast cancer who received NAC. According to the inclusion and exclusion criteria, 241 patients were finally included. The optimal cutoff of SIRI was $0.72 \times 10^{9} / \mathrm{L}$ (area under the ROC curve $[\mathrm{AUC}]=0.684,, 95 \%$ confidence interval $[\mathrm{CI}]=$ $0.592-0.775, p=0.000$ ) (Fig. 2). The median age at diagnosis was 48 years (range, 23-74). The low and high SIRI groups included $63(26.14 \%)$ and 178 patients $(73.86 \%)$, respectively. Most patients were diagnosed with cT2 lesions on the basis of tumor size (68.88\%), and $65.15 \%$ of patients had cN1-N3 lesions. Only $1.24 \%$ of tumors were well-differentiated (G1). Triple-negative breast cancer was detected in 53 patients $(22.00 \%)$. HER-2-positive was identified in 87 patients (36.10\%), and HR-positive was identified in 101 patients (41.90\%). Forty-eight patients (19.92\%) achieved pCR after NAC. The detailed clinicopathological parameters of all patients are presented in Table 1.

\section{Relationship between clinicopathological parameters and pCR}

After NAC, 48 patients achieved pCR. In the present study, several factors were related to pCR, such as BMI, clinical $\mathrm{T}$ and $\mathrm{N}$ staging, histological grade, molecular subtypes, SIRI, NLR and LMR (Table 2). Interestingly, patients with low BMI had a significantly higher pCR rate than those with high BMI. In addition, higher $\mathrm{pCR}$ 


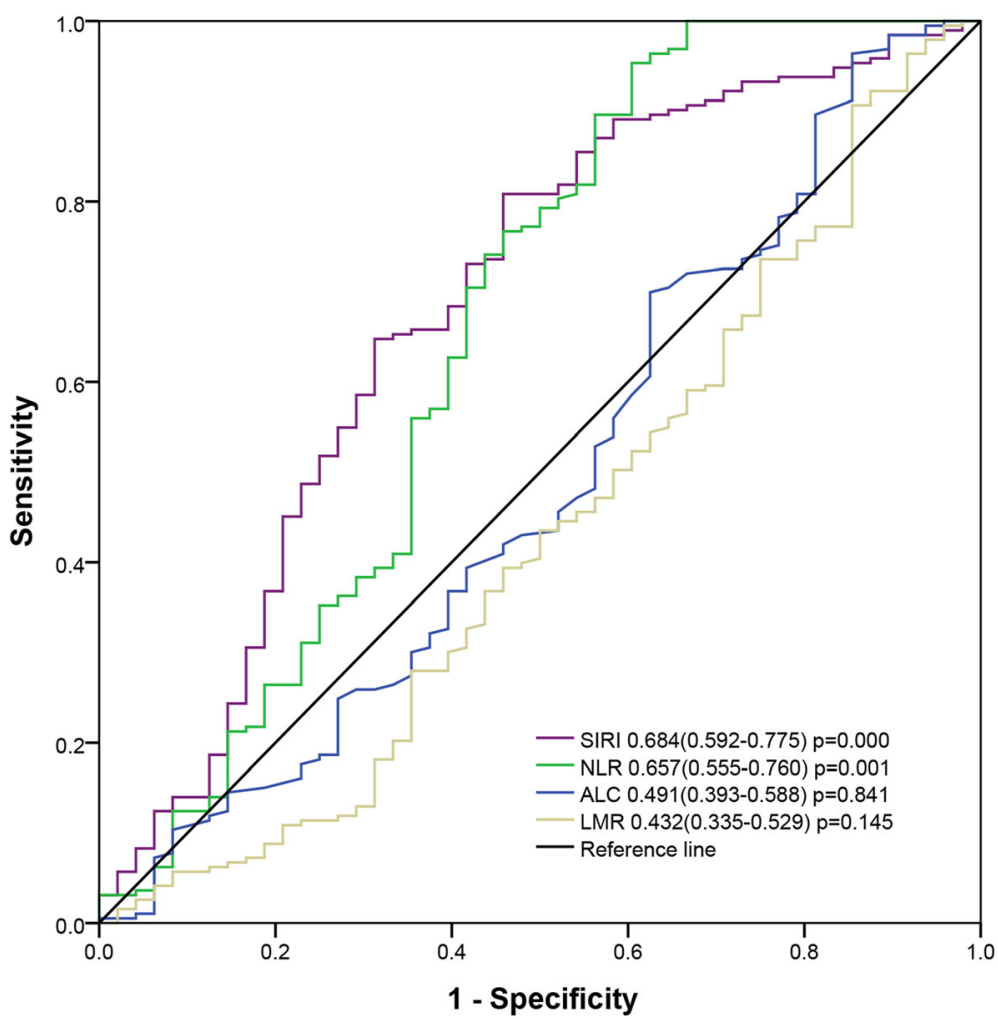

Fig. 2 Predictive ability of the SIRI was compared with NLR, ALC and LMR by ROC curves

rates were observed in patients with higher clinical $\mathrm{T}$ and $\mathrm{N}$ stages. Patients with triple-negative breast cancer and HER-2-positive breast cancer had higher pCR rates than those with HR-positive breast cancer. Furthermore, the pCR rate was higher in patients with low SIRI than in those with high SIRI. Consistently, patients with low NLR had a higher pCR rate. Additionally, the pCR rate was also higher in patients with high LMR. Multivariate analysis illustrated that only clinical $\mathrm{T}$ and $\mathrm{N}$ staging, NLR, and SIRI retained their importance (Table 3). The AUC for SIRI was larger than that for NLR (Fig. 2). Patients with SIRI $<0.72$ had an nearly 5-fold higher chance of achieving $\mathrm{pCR}$ than those with SIRI $\geq 0.72$ (odds ratio $=4.999,95 \% \mathrm{CI}=1.510-16.551, p=0.000$ ).

\section{Discussion}

Cancer-related inflammation is of great importance to the occurrence and development of tumors and resistance to chemotherapy [16]. As an indicator of inflammation, SIRI has been reported to be closely related to the prognosis in breast cancer. However, the correlation between SIRI and pCR in patients with breast cancer remains unclear. This study described the predictive value of SIRI for pCR.

In the present study, parameters such as SIRI, NLR, LMR, BMI, clinical $\mathrm{T}$ and $\mathrm{N}$ staging, histological grade, and molecular subtypes were significantly associated with pCR. However, multivariate analysis illustrated that only SIRI, NLR, and clinical $\mathrm{T}$ and $\mathrm{N}$ staging were independently predictive of $\mathrm{pCR}$ among those parameters. Inflammation cells have important anti-tumor functions. Neutrophils (both circulating and tumor-associated) can acquire an anti-tumor phenotype in the presence of interferon- $\beta$ or upon the inhibition of transforming growth factor- $\beta$ signaling $[17,18]$. Lymphocytes can suppress tumor growth through direct cytotoxicity, apoptosis induction, and angiogenesis inhibition [19]. Monocytes exert anti-tumor effects through phagocytosis, tumoricidal mediator secretion, lymphocyte recruitment, and differentiation into tumor-associated macrophages and dendritic cells [20]. Systemic inflammation can affect a patient's response to chemotherapeutic agents [21]. NLR has been introduced as a predictive factor for $\mathrm{pCR}$ in patients with breast cancer who receive NAC [22]. SIRI was reported to be related to prognosis in many cancer types such as nasopharyngeal cancer and pancreatic cancer [23, 24]. Consistent with previous reports, our study also found that SIRI can indicate the prognosis of breast cancer. This is also the first study reporting that SIRI is predictive of pCR. SIRI has been reported to reflect the status of the local immune response and systemic inflammation [10]. 
Table 1 Patients' clinicopathological parameters $(n=241)$

\begin{tabular}{l} 
Variables \\
\hline Age (years) \\
$\quad<48$ \\
$\quad \geq 48$ \\
Body mass index \\
$\quad<24$ \\
$\geq 24$ \\
Clinical T stage \\
T1 \\
T2 \\
T3-T4
\end{tabular}

\section{Clinical $\mathbf{N}$ stage}

$\begin{array}{ll}\text { No } & 84 \\ \text { N1-N3 } & 157\end{array}$

Grade

$\begin{array}{ll}\text { Grade1 } & 3 \\ \text { Grade2 } & 120 \\ \text { Grade3 } & 70 \\ \text { UN } & 48\end{array}$

Phenotype by IHC

$\begin{array}{lll}\text { HR-positive } & 101 & 41.90 \\ \text { HER-2-positive } & 87 & 36.10 \\ \text { Triple-negative } & 53 & 22.00\end{array}$

Ki67 proliferation index

$\begin{array}{ll}\leq 20 & 69 \\ >20 & 172\end{array}$

\section{Nac regimens}

$\begin{array}{ll}\text { Anthra based } & 39 \\ \text { Tax based } & 25\end{array}$

SIRI

$\begin{array}{ll}<0.72 & 63 \\ \geq 0.72 & 178\end{array}$

NLR

$\begin{array}{ll}<1.77 & 28 \\ \geq 1.77 & 213\end{array}$

LMR

$$
<5.38
$$$$
\geq 5.38
$$

ALC

$$
<1.57
$$$$
\geq 1.57
$$

Response to NAC

$$
\text { pCR }
$$$$
\mathrm{N}-\mathrm{pCR}
$$

132

109

Percent (\%)

44.81

55.19

51.90

48.10

10.79

68.88

20.33

34.85

65.15

1.24

49.79

29.05

19.92

4.90

6.10

28.63

71.37

5

77

78

28

213

201

40

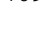

48

193

19.92

\begin{tabular}{|c|c|c|c|}
\hline Variables & $\mathrm{N}-\mathrm{pCR}$ & pCR (N, \%) & $P$-value \\
\hline \multicolumn{4}{|c|}{ Age (years) } \\
\hline$<48$ & 84 & $24(22.22)$ & 0.419 \\
\hline$\geq 48$ & 109 & $24(18.05)$ & \\
\hline \multicolumn{4}{|c|}{ Body mass index $(\mathrm{kg} / \mathrm{m} 2)$} \\
\hline$<24$ & 94 & $31(24.80)$ & 0.049 \\
\hline$\geq 24$ & 99 & $17(14.66)$ & \\
\hline
\end{tabular}

80.08
Table 2 Associations of clinicopathological parameters with pCR in breast cancer patients

\section{Clinical T stage}

$\begin{array}{llll}\text { T1 } & 16 & 10(38.46) & 0.043 \\ \text { T2 } & 137 & 29(17.47) & \\ \text { T3-T4 } & 40 & 9(18.37) & \end{array}$

\section{Clinical N stage}

$\begin{array}{llll}\text { No } & 47 & 37(44.05) & 0.000 \\ \text { N1-N3 } & 146 & 11(7.01) & \end{array}$

\section{Grade}

\begin{tabular}{|c|c|c|}
\hline HR-positive & 85 & $16(15.84)$ \\
\hline HER-2-positive & 72 & $15(17.24)$ \\
\hline Triple-negative & 36 & $17(32.07)$ \\
\hline \multicolumn{3}{|c|}{ Ki67 proliferation index } \\
\hline$\leq 20$ & 59 & $10(14.49)$ \\
\hline$>20$ & 134 & 38 (22.09) \\
\hline
\end{tabular}

$\begin{array}{llll}\text { Grade1 } & 2 & 1(33.33) & 0.013 \\ \text { Grade2 } & 104 & 16(13.33) & \\ \text { Grade3 } & 56 & 14(20.00) & \\ \text { UN } & 31 & 17(35.41)\end{array}$

\section{Phenotype by IHC}

\section{Nac regimens}

$\begin{array}{llll}\text { Anthra based } & 29 & 10(25.64) & 0.291 \\ \text { Tax based } & 18 & 7(28.00) & \\ \text { Anthra + Tax based } & 146 & 31(17.51) & \\ \text { SIRI } & & & \\ <0.72 & 37 & 26(41.27) & 0.000 \\ \geq 0.72 & 156 & 22(12.36) & \end{array}$

NLR

\begin{tabular}{lclll}
11.62 & NLR & & & \\
88.38 & $<1.77$ & 9 & $19(67.86)$ & 0.000 \\
& $\geq 1.77$ & 184 & $29(13.62)$ & \\
83.40 & LMR & & & \\
16.60 & $<5.38$ & 168 & $33(16.41)$ & 0.002 \\
& $\geq 5.38$ & 25 & $15(37.50)$ & \\
54.77 & ALC & & & \\
45.23 & $<1.57$ & 109 & $23(21.10)$ & 0.286 \\
& $\geq 1.57$ & 84 & $25(22.94)$ & \\
\hline
\end{tabular}


Table 3 Predictive factors for $\mathrm{pCR}$ in multivariate analyses

\begin{tabular}{|c|c|c|}
\hline Variables & Multivariate OR $(95 \% \mathrm{Cl})$ & $P$-value \\
\hline \multicolumn{3}{|c|}{ Body mass index $(\mathrm{kg} / \mathrm{m} 2)$} \\
\hline$<24$ & 1 & \\
\hline$\geq 24$ & $0.577(0.232-1.437)$ & 0.238 \\
\hline \multicolumn{3}{|l|}{ Clinical T stage } \\
\hline $\mathrm{T} 1$ & 1 & \\
\hline $\mathrm{T} 2$ & $0.276(0.082-0.927)$ & 0.037 \\
\hline T3-T4 & $0.221(0.053-0.927)$ & 0.039 \\
\hline \multicolumn{3}{|l|}{ Clinical $\mathbf{N}$ stage } \\
\hline No & 1 & \\
\hline N1-N3 & $0.063(0.022-0.176)$ & 0.000 \\
\hline \multicolumn{3}{|l|}{ Grade } \\
\hline Grade1 & 1 & \\
\hline Grade2 & $0.499(0.023-10.820)$ & 0.658 \\
\hline Grade3 & $0.698(0.030-15.977)$ & 0.822 \\
\hline UN & $2.186(0.093-51.421)$ & 0.628 \\
\hline \multicolumn{3}{|c|}{ Phenotype by IHC } \\
\hline HR-positive & 1 & \\
\hline HER-2-positive & $0.658(0.220-1.969)$ & 0.454 \\
\hline Triple-negative & $2.110(0.697-6.385)$ & 0.186 \\
\hline \multicolumn{3}{|l|}{ SIRI } \\
\hline$\geq 0.72$ & 1 & \\
\hline$<0.72$ & 4.999 (1.510-16.551) & 0.008 \\
\hline \multicolumn{3}{|l|}{ NLR } \\
\hline$\geq 1.77$ & 1 & \\
\hline$<1.77$ & $7.257(2.122-24.818)$ & 0.002 \\
\hline \multicolumn{3}{|l|}{ LMR } \\
\hline$<5.38$ & 1 & \\
\hline$\geq 5.38$ & $0.616(0.181-2.090)$ & 0.437 \\
\hline
\end{tabular}

Compared to NLR, SIRI is more comprehensive because monocytes were also included in the model. In addition, the interactions among the three inflammatory cell types might enhance the prognostic value of the indicator. In the present study, the AUC for SIRI was larger than that for NLR, indicating that the prognostic value of the SIRI for $\mathrm{pCR}$ was superior to that of NLR. Although some detection methods, such as NLR, MRI, PET/CT, have been reported to predict $\mathrm{pCR}$, in actual clinical practice no detection method has been used to predict $\mathrm{pCR}[25,26]$. Hence, we must keep exploring new indicators for clinical practice. Compared to NLR, SIRI is a new comprehensive indicator for $\mathrm{pCR}$ with greater potential value for clinical practice. In summary, SIRI has more advantages than NLR.

Some studies and clinical trials illustrated that imaging, positron emission tomography, and gene expression profiling such as PIK3CA mutation can predict the outcome of neoadjuvant chemotherapy [27-29]. However, these methods or indicators are costly and not conducive to general clinical implementation. SIRI, as an immune/inflammation index, is based on the counts of peripheral blood neutrophils, monocytes, and lymphocytes, and it has a simple and inexpensive procedure. In this study, we provided evidence that SIRI was independently predictive of pCR. By calculating SIRI, we can predict whether a patient will quickly achieve $\mathrm{pCR}$, permitting the selection of an optimal treatment strategy for each patient. In addition, we can also save medical resources and reduce the financial burden of patients.

The pathophysiological functions of peripheral venous blood cells, such as neutrophils, monocytes and lymphocytes, may explain the mechanisms by which SIRI is predictive of $\mathrm{pCR}$ in patients with breast cancer receiving NAC. First, neutrophils produce substances, such as chemokines and/or cytokines, matrix-degrading proteases and reactive oxygen species, which can alter tumor growth and aggressiveness. Several studies indicated that neutrophils promote tumor progression through matrix degradation and cancer cell proliferation [16]. Second, monocytes, especially tumor-associated macrophages, are the mediators of the link between inflammation and cancer. They also play multiple roles in various stages of cancer development [20]. Third, lymphocytes can inhibit tumor cell proliferation and migration by inducing cytotoxic cell death, which plays a key role in tumor immune monitoring and defense [30]. For patients with cancer and fever exceeding $38{ }^{\circ} \mathrm{C}$, night sweats, fatigue, weight loss of more than $5 \%$ (so-called B symptoms), and malnutrition, the clinical outcome is poor, and this outcome is related to increased circulating cytokine concentrations [31]. The levels of these factors reflect the host's immune response to tumors. These reasons may explain why patients with higher SIRI have lower pCR rate.

Different studies reported that SIRI is closely related to prognosis in many tumors. Chen et al. found in nasopharyngeal carcinoma that patients with higher SIRI had significantly shorter OS than those with lower SIRI [24]. In addition, in postmenopausal women with breast cancer, Hua et al. reported that patients with low SIRI had significantly longer OS than those with high SIRI [32]. Consistently, Chen et al. observed that among patients with breast cancer treated with NAC, those with low SIRI had longer DFS and OS, but they did not find a statistical correlation between SIRI and pCR, which contradicts our results [11]. In patients with breast cancer, different ages, stages and phenotypes also correspond to different immune responses, therefore leading to different SIRIs. We believe that the differences in the characteristics of the enrolled population explain the differences between our results and previous findings. Therefore, multi-center prospective clinical studies are required to further confirm our results. 
This study confirmed the predictive value of SIRI for pCR, but some limitations must be addressed. First, this was a relatively small, single-center, and retrospective study, and its conclusions may be biased. Second, there may have been deviations in the assessment of the inflammatory status. Various internal and external factors can affect SIRI, such as acute inflammation, chronic infection and lifestyle. More importantly, we failed to obtain follow-up data to assess the correlation of SIRI with DFS and OS. Therefore, large multi-center studies are needed for further confirmation.

\section{Conclusions}

SIRI is a new comprehensive index based on the total numbers of peripheral neutrophils, monocytes, and lymphocytes; thus it can provide a non-invasive, easily accessible, reproducible, cost-effective and feasible method for predicting the response to NAC and assist physicians in formulating personalized treatment strategies.

\section{Abbreviations}

ALC: The Absolute Lymphocyte Count; AUC: Area Under The ROC Curve; Cl: Confidence Interval; L: Lymphocyte; LMR: The Lymphocyte-Monocyte Ratio; M: Monocyte; N: Neutrophil; NLR: The Neutrophil-Lymphocyte Ratio; NAC: Neoadjuvant Chemotherapy; pCR: pathological Complete Response; ROC: Receiver Operating Characteristic; SIRI: Systemic Inflammation Response Index

\section{Supplementary Information}

The online version contains supplementary material available at https://doi. org/10.1186/s12885-021-08458-4

Additional file 1: Supplementary Table 1. Associations of

clinicopathological features with SIRI in breast cancer.

\section{Acknowledgements}

We thank Joe Barber Jr., PhD, from Liwen Bianji, Edanz Editing China (www liwenbianji.cn/ac), for basic language editing of a draft of this manuscript.

\section{Authors' contributions}

Jie Dong wrote the manuscript. Qingqing Sun carried out the collection and assembly of data. Yueyin Pan and Nannan Lu provided suggestions for the modification of this article. Qiong Zhou conceived of the study and participated in its design. Xinghua Han and Qiong Zhou coordinated and approved the final manuscript. All authors read and approved the final manuscript.

\section{Funding}

This work was partially supported by Anhui Provincial Key Research (1804 h08020259) and Anhui Province Natural Science Foundation (1908085MH286).

\section{Availability of data and materials}

The datasets used and/or analyzed during the current study are available from the corresponding author on reasonable request.

\section{Declarations}

\section{Ethics approval and consent to participate}

The ethics committee of The First Affiliated Hospital of USTC approved the study. And informed consent was exempted by the ethics committee of The First Affiliated Hospital of USTC due to the retrospective nature of the study.
All methods were conducted in accordance with relevant guidelines and regulations.

\section{Consent for publication}

Not applicable.

\section{Competing interests}

The authors declare that they have no competing interests.

\section{Author details}

${ }^{1}$ Department of Medical Oncology, Anhui Provincial Hospital affiliated to Anhui Medical University, Hefei 2300001, Anhui Province, China. ${ }^{2}$ Department of Medical Oncology, The First Affiliated Hospital of USTC, Division of Life Sciences and Medicine, University of Science and Technology of China, Hefei 230001, Anhui Province, China.

Received: 18 January 2021 Accepted: 7 June 2021

Published online: 14 June 2021

\section{References}

1. Miller KD, Nogueira L, Mariotto AB, Rowland JH, Yabroff KR, Alfano CM, et al. Cancer treatment and survivorship statistics, 2019. CA Cancer J Clin. 2019; 69(5):363-85. https://doi.org/10.3322/caac.21565

2. Rubens RDSS, Tong D, Winter PJ, Knight RK, Hayward JL. Combined chemotherapy and radiotherapy for locally advanced breast cancer. Eur J Cancer. 1980;16(3):351-6. https://doi.org/10.1016/0014-2964(80)90352-7.

3. Colomer R, Saura C, Sanchez-Rovira P, Pascual T, Rubio IT, Burgues O, et al. Neoadjuvant Management of Early Breast Cancer: a clinical and investigational position statement. Oncologist. 2019;24(5):603-11. https:// doi.org/10.1634/theoncologist.2018-0228.

4. National Comprehensive Cancer Network. NCCN Clinical Practice Guidelines in Oncology -Breast Cancer 2019. Available from: https://www.nccn.org/ professionals/physician gls/pdf/breast.pdf. Accessed 22 Apr 2019.

5. Prowell TM, Pazdur R. Pathological complete response and accelerated drug approval in early breast cancer. N Engl J Med. 2012;366(26):2438-41. https:// doi.org/10.1056/NEJMp1205737.

6. Steenbruggen TG, van Ramshorst MS, Kok M, Linn SC, Smorenburg CH, Sonke GS. Neoadjuvant therapy for breast Cancer: established concepts and emerging strategies. Drugs. 2017;77(12):1313-36. https://doi.org/10.1007/s4 0265-017-0774-5.

7. Cortazar P, Zhang L, Untch M, Mehta K, Costantino JP, Wolmark N, et al. Pathological complete response and long-term clinical benefit in breast cancer: the CTNeoBC pooled analysis. Lancet. 2014;384(9938):164-72. https://doi.org/10.1016/S0140-6736(13)62422-8.

8. Dan J, Tan J, Huang J, Zhang X, Guo Y, Huang Y, et al. The dynamic change of neutrophil to lymphocyte ratio is predictive of pathological complete response after neoadjuvant chemotherapy in breast cancer patients. Breast Cancer. 2020:27(5):982-8. https://doi.org/10.1007/s12282-020-01096-X.

9. Peng Y, Chen R, Qu F, Ye Y, Fu Y, Tang Z, et al. Low pretreatment lymphocyte/monocyte ratio is associated with the better efficacy of neoadjuvant chemotherapy in breast cancer patients. Cancer Biol Ther. 2020;21(2):189-96. https://doi.org/10.1080/15384047.2019.1680057.

10. Qi Q, Zhuang L, Shen Y, Geng Y, Yu S, Chen H, et al. A novel systemic inflammation response index (SIRI) for predicting the survival of patients with pancreatic cancer after chemotherapy. Cancer. 2016;122(14):2158-67. https://doi.org/10.1002/cncr.30057.

11. Chen L, Kong X, Wang Z, Wang X, Fang Y, Wang J. Pretreatment systemic inflammation response index in patients with breast Cancer treated with neoadjuvant chemotherapy as a useful prognostic Indicator. Cancer Manag Res. 2020;12:1543-67. https://doi.org/10.2147/CMAR.S235519.

12. Li S, Lan X, Gao H, Li Z, Chen L, Wang W, et al. Systemic inflammation response index (SIRI), cancer stem cells and survival of localised gastric adenocarcinoma after curative resection. J Cancer Res Clin Oncol. 2017; 143(12):2455-68. https://doi.org/10.1007/s00432-017-2506-3.

13. Wang L, Zhou Y, Xia S, Lu L, Dai T, Li A, et al. Prognostic value of the systemic inflammation response index (SIRI) before and after surgery in operable breast cancer patients. Cancer Biomark. 2020;28(4):537-47. https:// doi.org/10.3233/CBM-201682.

14. Wolff AC, Hammond MEH, Allison KH, Harvey BE, Mangu PB, Bartlett JMS, et al. Human epidermal growth factor receptor 2 testing in breast Cancer: American Society of Clinical Oncology/College of American Pathologists 
Clinical Practice Guideline Focused Update. J Clin Oncol. 2018;36(20):210522. https://doi.org/10.1200/JCO.2018.77.8738.

15. von Minckwitz G, Untch M, Blohmer JU, Costa SD, Eidtmann H, Fasching PA, et al. Definition and impact of pathologic complete response on prognosis after neoadjuvant chemotherapy in various intrinsic breast cancer subtypes. J Clin Oncol. 2012;30(15):1796-804. https://doi.org/10.1200/JCO.2011.38. 8595.

16. Galdiero MR, Marone G, Mantovani A. Cancer Inflammation and Cytokines. Cold Spring Harb Perspect Biol. 2018;10(8):a028662.

17. Andzinski L, Kasnitz N, Stahnke S, Wu CF, Gereke M, von Kockritz-Blickwede $M$, et al. Type I IFNs induce anti-tumor polarization of tumor associated neutrophils in mice and human. Int J Cancer. 2016;138(8):1982-93. https:// doi.org/10.1002/ijc.29945.

18. Fridlender ZG, Sun J, Kim S, Kapoor V, Cheng G, Ling L, et al. Polarization of tumor-associated neutrophil phenotype by TGF-beta: "N1" versus "N2" TAN. Cancer Cell. 2009;16(3):183-94. https://doi.org/10.1016/j.ccr.2009.06.017.

19. Morrow ES, Roseweir A, Edwards J. The role of gamma delta T lymphocytes in breast cancer: a review. Transl Res. 2019;203:88-96. https://doi.org/10.101 6/j.trsl.2018.08.005.

20. Olingy CE, Dinh $\mathrm{HQ}$, Hedrick CC. Monocyte heterogeneity and functions in cancer. J Leukoc Biol. 2019;106(2):309-22. https://doi.org/10.1002/JLB.4RI081 8-311R.

21. Tong YS, Tan J, Zhou XL, Song YQ, Song YJ. Systemic immune-inflammation index predicting chemoradiation resistance and poor outcome in patients with stage III non-small cell lung cancer. J Transl Med. 2017;15(1):221. https://doi.org/10.1186/s12967-017-1326-1.

22. Corbeau I, Jacot W, Guiu S. Neutrophil to Lymphocyte ratio as prognostic and predictive factor in breast cancer patients: a systematic review. Cancers (Basel). 2020;12(4):958.

23. Pacheco-Barcia V, Mondejar Solis R, France T, Asselah J, Donnay O, Zogopoulos G, et al. A systemic inflammation response index (SIRI) correlates with survival and predicts oncological outcome for mFOLFIRINOX therapy in metastatic pancreatic cancer. Pancreatology. 2020;20(2):254-64. https://doi.org/10.1016/.jpan.2019.12.010

24. Chen Y, Jiang W, Xi D, Chen J, Xu G, Yin W, et al. Development and validation of nomogram based on SIRI for predicting the clinical outcome in patients with nasopharyngeal carcinomas. J Investig Med. 2019;67(3):6918. https://doi.org/10.1136/jim-2018-000801.

25. Chen L, Yang Q, Bao J, Liu D, Huang X, Wang J. Direct comparison of PET/ $C T$ and MRI to predict the pathological response to neoadjuvant chemotherapy in breast cancer: a meta-analysis. Sci Rep. 2017;7(1):8479. https://doi.org/10.1038/s41598-017-08852-8.

26. Al-Hattali S, Vinnicombe SJ, Gowdh NM, Evans A, Armstrong S, Adamson D, et al. Breast MRI and tumour biology predict axillary lymph node response to neoadjuvant chemotherapy for breast cancer. Cancer Imaging. 2019; 19(1):91. https://doi.org/10.1186/s40644-019-0279-4.

27. Fowler AM, Mankoff DA, Joe BN. Imaging neoadjuvant therapy response in breast Cancer. Radiology. 2017;285(2):358-75. https://doi.org/10.1148/radiol.2 017170180.

28. Chen S, Ibrahim NK, Yan Y, Wong ST, Wang H, Wong FC. Complete metabolic response on interim (18)F-Fluorodeoxyglucose positron emission tomography/ computed tomography to predict Long-term survival in patients with breast Cancer undergoing neoadjuvant chemotherapy. Oncologist. 2017;22(5):526-34. https:/doi.org/10.1634/theoncologist.2016-0334.

29. Fan H, Li C, Xiang Q, Xu L, Zhang Z, Liu Q, et al. PIK3CA mutations and their response to neoadjuvant treatment in early breast cancer: a systematic review and meta-analysis. Thorac Cancer. 2018;9(5):571-9. https://doi.org/1 0.1111/1759-7714.12618.

30. Mantovani A, Allavena P, Sica A, Balkwill F. Cancer-related inflammation. Nature. 2008:454(7203):436-44. https://doi.org/10.1038/nature07205.

31. Diakos $\mathrm{Cl}$, Charles KA, McMillan DC, Clarke SJ. Cancer-related inflammation and treatment effectiveness. Lancet Oncol. 2014;15(11):e493-503. https:// doi.org/10.1016/S1470-2045(14)70263-3.

32. Hua $X$, Long $Z Q$, Huang $X$, Deng JP, Wen $W$, He ZY, et al. The preoperative systemic inflammation response index (SIRI) independently predicts survival in postmenopausal women with breast cancer. Curr Probl Cancer. 2020; 44(4):100560. https://doi.org/10.1016/j.currproblcancer.2020.100560.

\section{Publisher's Note}

Springer Nature remains neutral with regard to jurisdictional claims in published maps and institutional affiliations.

Ready to submit your research? Choose BMC and benefit from:

- fast, convenient online submission

- thorough peer review by experienced researchers in your field

- rapid publication on acceptance

- support for research data, including large and complex data types

- gold Open Access which fosters wider collaboration and increased citations

- maximum visibility for your research: over $100 \mathrm{M}$ website views per year

At BMC, research is always in progress.

Learn more biomedcentral.com/submissions 